\title{
Higher Tourism Education in English - where and why?
}

Rico Maggi, University of Lugano rico.maggi@lu.unisi.ch

Loredana Padurean, University of Lugano Loredana.padurean@lu.unisi.ch

\begin{abstract}
Purpose

The future growth of international tourism is challenged by concerns of political instability, safety, socio-economics and environmental impact. Furthermore, globalization has increased competition in tourism markets, and destinations are exposed to tough price competition on homogenized products by rivals worldwide. Given these challenges and the desire by locales for sustainable tourism development, human resource development is critical to the success of tourism in many markets. As countries and regions invest more in higher education for tourism, many of them seem to be launching these programs in English to broaden their market appeal. However, the market for higher tourism education in English (HTEE) is highly competitive and progressively global, so launching a program in English opens a school to greater competition as a price for reaching a wider audience. The purpose of this paper is to look at how tourism, wealth and higher education are linked, and how the location of HTEE is related to the importance and role of tourism in a country.
\end{abstract}

\section{Approach}

This research focuses on master programs in tourism taught in English. Starting from the current location of programs we develop two scenarios of the future spatial distribution of higher education in tourism in an increasingly global and competitive market.

\section{Findings}

In a first scenario, one where students are more mobile than teachers, programs will be concentrated in a few wealthy countries, which are also important tourism countries. In the alternative scenario, programs and teachers will follow students and, consequentially, distribution of higher education as well as tourism development and wealth will be distributed in a more equitable way.

\section{Research limitations}

This research is limited to a set of graduate programs in tourism taught in English. Future research should expand the data set to bachelor degrees as well as programs in national languages.

Key words: higher education, globalization, international tourism

Article Type: Conceptual paper

\section{Introduction}

Tourism represents an important and highly concentrated part of the world economy. As Figure 1 demonstrates, 5\% (or 10 countries) account for 50\% of world international tourism in terms of the sum of departures and arrivals, and the top $10 \%$ tourism economies produce $70 \%$ of world tourism. The top ranked countries all represent highly 
developed and diversified "Western" countries. Moreover, more than $50 \%$ of international tourism, in terms of departures as well as arrivals, involves European countries. This corresponds, as will be demonstrated, to 50\% of the HTEE programs being offered by European countries.

Figure 1: Distribution of Tourism among countries

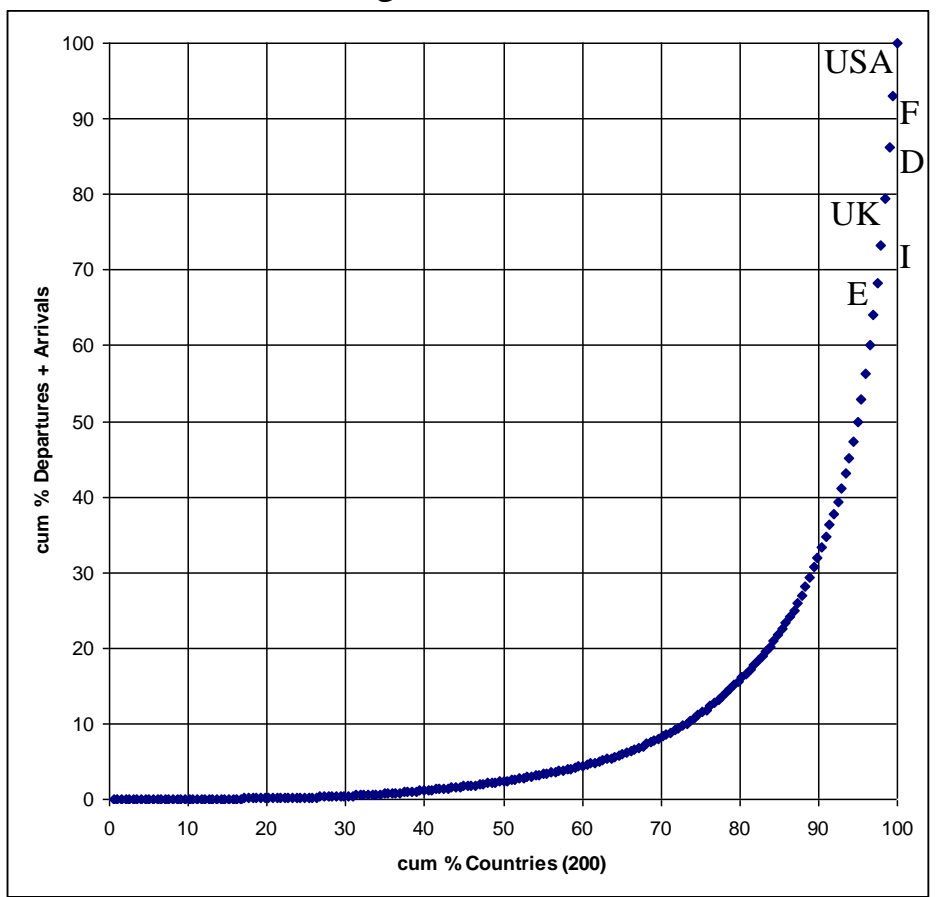

Data source: Worldmapper ( http://www.sasi.group.shef.ac.uk/worldmapper/)

Distinguishing between departures and arrivals of international tourists worldwide (in absolute terms) gives some further insight into the geography of tourism. An outer sphere in Figure 2 containing the most important tourism countries stretches from "countries for tourists" like France, Spain and Italy and to a lesser extent China, dominating international arrivals, to "countries of tourists" like Germany and UK and the United States, dominating international departures. A second tier of countries important for tourism is represented by Poland, the Czech Republic and Malaysia. However these countries vanish in the crowd below and are substituted by Japan in a similar position when arrivals and departures are substituted by expenditure and receipts (otherwise the picture for monetary values gives a similar picture.) Figure 2 also confirms the high concentration of tourism, with three to four countries dominating departures and arrivals, respectively. Looking at the names of these countries it becomes obvious that tourism is also linked to wealth. Tourism expenditures as well as receipts per country are strongly correlated with per capita GDP as demonstrated by figures A1 and A2 in the Appendix. 
Figure 2: Tourism arrivals and departures worldwide

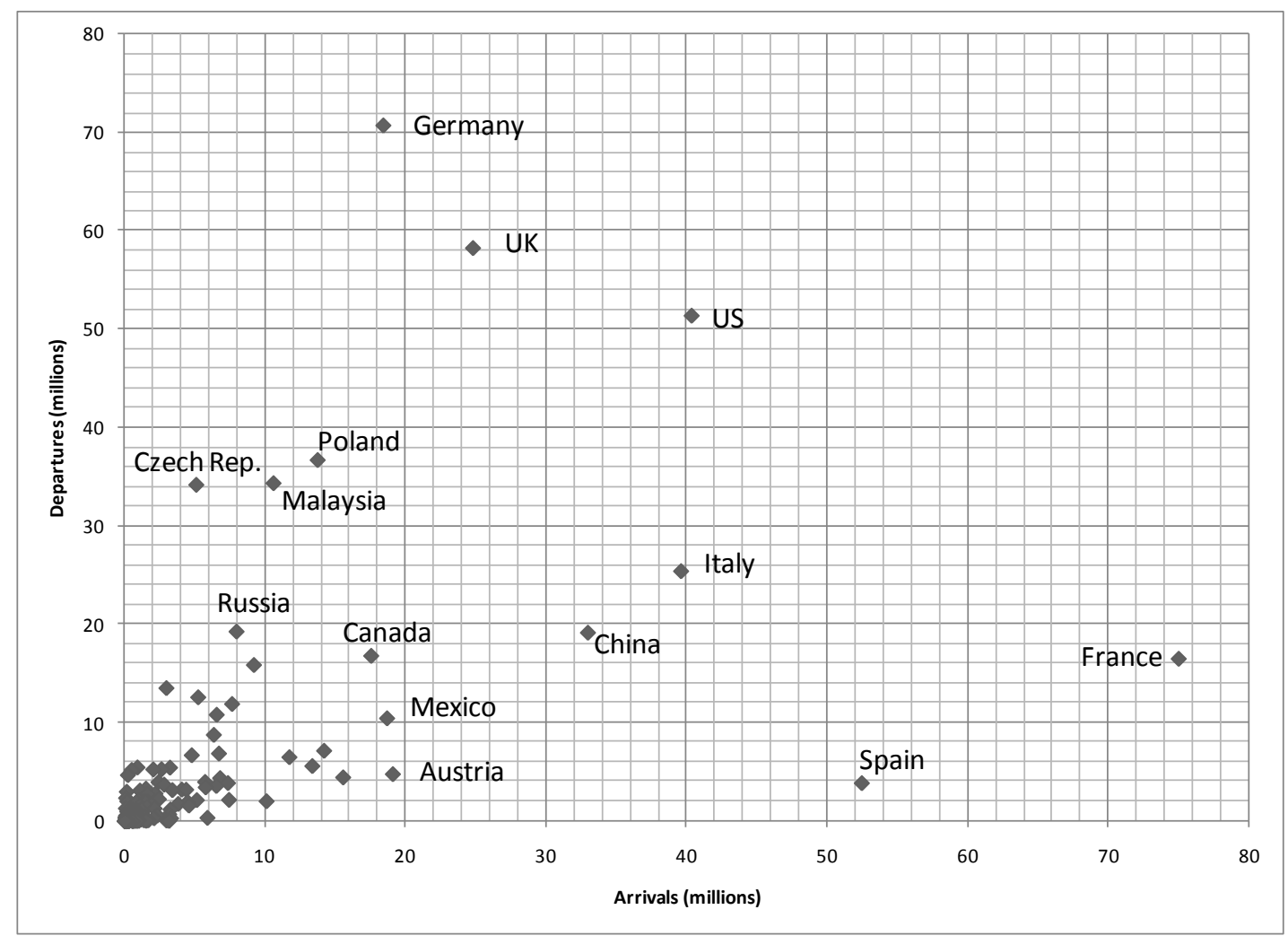

We seek to explore how the importance of tourism is linked to HTEE. While all seven of the most important countries have such programs (see below), many of those "in the cloud", i.e. less important in absolute terms, have them as well. This has to do, on the one hand, with the fact that many countries like e.g. Austria and Switzerland may not be important in absolute but they are so in relative terms, e.g. Switzerland being relatively important for tourism and tourism being important for Austria. On the other hand, as we will demonstrate, HTEE, like higher education in general, is also closely linked to the wealth of a country.

The relationship between higher education, research and economic development on a country level is a classically important in economic literature on endogenous growth where human capital is a key driver of development. Endogenous growth theory (for an overview see Barro \& Sala-i-Martin 1999) considers knowledge in the form of human capital accumulation, which is itself a consequence, among other things, of education, as an important driver of growth. On a cross country level there is important evidence for 
the role of human capital as e.g. demonstrated by Benhabib \& Spiegel 1994. More specifically, there is empirical literature on education and growth (e.g. Stevens \& Weale 2003) which demonstrates a positive impact of education. However, the relevant question in our context is whether this general result holds also for higher education in tourism. On the question of higher education in general, formulated by Stevens \& Wale as "What sort of education?" the answer is mixed. Wolff \& Gittelman (1993) find that among rich nations tertiary education has a positive impact on wealth, while in poorer economies what counts is primary education. This distinction is of relevance here as our question is whether the distribution of HTEE programs will enhance convergence or lead to divergence among countries. The competitive global market for higher education is dominated by programs taught in English for two reasons. First, the vast majority of top ranked universities worldwide (and programs in tourism, by the way) are to be found in Anglo-Saxon countries, above all the US and UK. Second, the role of English as lingua franca has taken root not only in top research institutes, but also, increasingly in higher education generally. With the increasing mobility and the globalization of the educational market, students are moving to the best addresses from anywhere, on condition that the teaching language is English. Undoubtedly, national and regional markets of importance also exist, but only the English speaking higher education programs can be considered to be directly exposed to global competition.

We have seen very little research concentrating on the location of programs of higher education in tourism in relation to tourism destinations or origins. One exception is the work on vocational training in tourism and local/regional development for single countries (e.g. Lam \& Xiao 2000 for the case of China). More interest can be noted around the theme of educational tourism (see e.g. Ritchie 2003), but this work focuses on tourism experiences aimed explicitly at educating the tourist, a distinctly different issue. The scarcity of interest in the issue might be related to a historical interest by many tourism researchers in local or regional, rather than global issues. For us, a key question is whether HTEE will increasingly be concentrated among wealthy, developed countries or whether there is a chance that tourism clusters might arise also in developing tourism countries. More specifically, as many small destinations are poor countries, the question is whether higher education and the industrial dynamics linked to it can evolve in these countries, or whether education and human capital investments will primarily be attracted to rich origin countries.

In what follows we will first discuss the tourism relevance of countries and describe the distribution of HTEE among types of countries. We will then present a simple model of tourism development and HTEE location and apply this in a third moment to speculate on the future distribution of HTEE among countries. Finally we will draw some conclusions.

\section{"Importance of Tourism" and the location of HTEE}

Our work is based on a dataset comprising 112 English-language, Master Programs in tourism and travel, offered by private and public universities, with a minimum length of 2 semesters of study. These 112 HTEE programs, active in fall 2006, are distributed among 
23 countries. Programs with curricula of hospitality only as well as the hotel schools and other institutions of Vocational Training in Tourism (VTT) were excluded. The first question posed here is whether these programs are distributed among countries according to the importance of tourism in those countries. Importance in tourism can be different with respect to arrivals (destinations) and departures (source countries). Furthermore, looking at absolute figures provides a different kind of information than considering the tourism per country in terms of density. Table 1 provides insight into our question on the distribution of HTEE with regard to the absolute importance of tourism and completes the picture with the wealth of a country (note that wealth is in per capita terms).

Table 1: Distribution of HTEE by Countries and their Rankings for Tourism and Wealth

\begin{tabular}{|c|c|c|c|c|}
\hline Country & $\begin{array}{c}\text { HTEE } \\
\text { \# schools }\end{array}$ & $\begin{array}{c}\text { Rank Arrivals } \\
\text { in absolute } \\
\text { terms }\end{array}$ & $\begin{array}{c}\text { Rank } \\
\text { Departures } \\
\text { in absolute } \\
\text { terms }\end{array}$ & $\begin{array}{c}\text { Rank GDP per } \\
\text { Capita (PPP) }\end{array}$ \\
\hline UK & 36 & 6 & 2 & 26 \\
\hline USA & 31 & 3 & 3 & 4 \\
\hline Australia & 7 & 37 & 42 & 13 \\
\hline France & 4 & 1 & 11 & 17 \\
\hline Canada & 3 & 10 & 10 & 9 \\
\hline Netherlands & 3 & 18 & 12 & 11 \\
\hline New Zealand & 3 & 54 & 66 & 30 \\
\hline Switzerland & 3 & 25 & 10 & 6 \\
\hline China & 2 & 5 & 9 & 121 \\
\hline Germany & 2 & 9 & 1 & 15 \\
\hline Ireland & 2 & 23 & 32 & 3 \\
\hline Italy & 2 & 4 & 7 & 19 \\
\hline Korea & 2 & 34 & 21 & 42 \\
\hline Spain & 2 & 2 & 36 & 31 \\
\hline Sweden & 2 & 20 & 115 & 27 \\
\hline Thailand & 2 & 17 & 53 & 74 \\
\hline Austria & 1 & 71 & 29 & 10 \\
\hline Belgium & 1 & 24 & 20 & 14 \\
\hline Croatia & 1 & 21 & 50 & 58 \\
\hline Hong Kong & 1 & 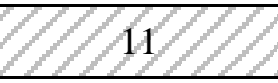 & 31 & 118 \\
\hline
\end{tabular}




\begin{tabular}{|c|c|c|c|c|}
\hline India & 1 & 51 & 34 & 189 \\
\hline Mexico & 1 & 8 & 17 & 64 \\
\hline
\end{tabular}

The table is based on the University of Sheffield's Sasi group database Worldmapper (http://www.sasi.group.shef.ac.uk/worldmapper/) which provides a vast amount of data for 200 countries. The figures are for the years 2002 or 2003. GDP per Capita is measured in USD purchasing power parity units. The first column contains the countries with HTEE programs ordered by the number of those programs offered as presented in column two. Columns three to five reveal the respective ranks of each country among all 200 countries for the variable in question. To enhance reading, three kinds of shading have been applied to the table. Vertical hatch indicates countries where English is the only or primary native language. These countries offer 82 out of 112 programs due to the above mentioned "natural advantage" regarding HTEE. The other two shadings have been applied to countries which are ranked in the top 20 (top 10\%) regarding their importance for all three criteria (horizontal hatch) or for at least one of them (diagonal hatch). The four horizontally hatched countries are all wealthy and important for tourism in absolute terms regarding departures as well as arrivals. They account together for 11 HTEE programs. The diagonally hatched group contains countries that are important for tourism either as destinations or as source markets (or both) but are not simultaneously also wealthy. More specifically, China, Sweden and Mexico are important as destinations and origins but not among the top 20 in terms of wealth while Switzerland and Belgium are wealthy and above all important as source markets. Austria and Hong Kong, on the other hand, are important and at the same time wealthy destinations, and finally Spain and Thailand are simply important as destinations. The diagonally hatched group offers 15 HTEE programs. The remaining countries, namely Korea, Croatia and India, offering 4 HTEE programs are not among the top 20 regarding tourism and wealth.

In summary: English speaking countries plus the four most important and wealthy other countries provide 93 programs, or similarly, only four out of 112 programs are offered by countries which are not in the top 20 tourism countries according to one of the two aspects. We therefore conclude that HTEE is closely related to the importance of tourism. Moreover, 11 out of 22 countries offering HTEE are among the 20 richest in the world and only 5 are not among the $25 \%$ wealthiest. Hence, provision of HTEE is also linked to wealth. From a more geographical point, finally, Europe, accounting for more than half of international tourism departures as well as arrivals offers also more than half of the HTEE programs. Also, out of the 112 HTEE programs in our database (see below) only 7 are located in non-OECD member countries. The reason for this is also historical. Like for the rest of the economy, economic history over the last centuries has been dominated by the "Old Continent" and later the United States (see e.g. Landes 1998). Also the history of tourism has for a long time been a European affair, Europe being a continent of many countries with different cultures, language, climate and topography, relatively short distances and continuous innovations in transport.

These findings lead to the question of the future distribution of tourism, wealth and HTEE. Over the past few decades, higher education has become a global phenomenon available around the world to a degree unimaginable to earlier generations. Once the 
exclusive preserve of elites, today one speaks of a "massification" of higher education. With the political changes in Europe, Asia, and the Bologna reforms ${ }^{1}$ that intend to unify the models of higher education programs, the world is becoming more competitive for institutions of higher education. In this environment of international competition, many universities face a more severe challenge to market themselves to students in a global marketplace. This reality pushes higher education institutions into internationalization strategies, but also national, regional and local governments become interested in promoting their territories as education destinations (Cubillo, Sanchez and Cervino, 2006) attracting a relevant share of the $3-5$ million international students that are mobile and interested in travelling, leaving home and experiencing new cultures (Blight, 1995).

The question is, hence, whether the current concentration of programs in strong origins/destination will be reinforced by the economic logics of global markets for tourism and education. We start answering this question by again looking at the distribution of HTEE programs from a competitiveness point of view. Competitiveness from a destination perspective regards the various factors influencing the attractiveness of a destination as measured among other things by the tourism competitiveness indicator proposed by the World Economic Forum (WEF). Competitiveness as an origin, i.e. being a country of tourists, is directly linked to the wealth of a country. Confronting the economic potential of countries in terms of GDP per capita with the Tourism Competitiveness Index (TCI), for the countries offering HTEE the picture presented in Figure 3 emerges. The message is again very straightforward: 12 countries offering HTEE are rich and at the same time highly competitive in the tourism market and it can be reasonably assumed that they will be defending their position on the HTEE market. Two less wealthy countries, Spain and New Zealand, are highly competitive, while 6 out of 22 countries offering HTEE exhibit a below average competitiveness and wealth. The question is what the prospects are for HTEE programs in these countries. In what follows we will therefore propose an economic reasoning about economic growth and HET.

1 The Bologna Declaration of 19 June 1999 
Figure 3: Distribution of HTEE among countries

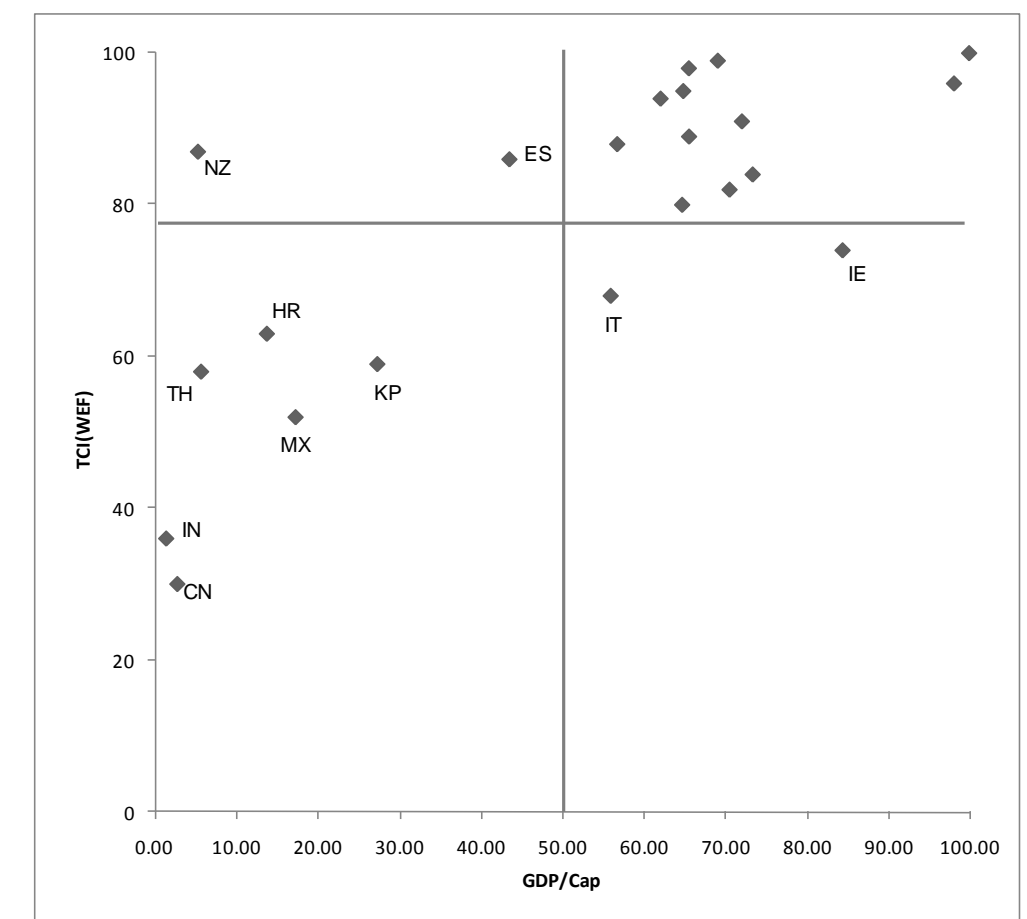

Data source: WEF 2007, Worldmapper ( http://www.sasi.group.shef.ac.uk/worldmapper/ )

\section{HTEE and economic growth - two scenarios}

The question we want to raise regards the dynamics behind the development of tourism and the supply of education in tourism, especially higher education. Our reflections start from economic growth and outgoing tourism. Tourism is an activity that increases with income. As a consequence, rich countries create a lot of outgoing tourism. As the economy and outgoing tourism grow, the local outgoing tourism industry will cater for increasing demand for the "get there" 2 phase of the tourism experience, i.e. information on destinations and products, transport and tour operators. This will create a demand for research and consulting for this growing sector. In parallel an increasing population of tourists will become interested in the phenomenon of tourism and create a demand for product and services offered by a workforce with higher education in tourism. This will develop into a dynamic process in the wealthy origin countries (like Austria, Germany, Belgium, Switzerland in our data set) where HTEE will become an important element of university education and research as a strategy to open to a broader, more competitive market.

\footnotetext{
${ }^{2}$ For the construction of the Lugano Tourism Indicator LTI the tourism experience has been subdivided into three stages, get there (information, transport), stay there (sleeping, eating) and live there (attractions, events, etc.) see Maggi \& Croce 2005.
} 
The growing tourism arrivals in destination countries will start a similar process in the "stay there" phase. Demand for hotel and restaurant services will make the sector grow, and via the local labor market create a demand for vocational training in tourism (VTT), especially in the hospitality segment. Paid labor opportunities in poor countries are scarce and tourism is often an important sector offering money for labor. Salaries, working conditions and social prestige in tourism are relatively high as compared to other occupations in poor countries. Foreign direct investors offer therefore relatively safe, clean and prestigious work and express a demand for well trained employees. The native population invests in human capital in hospitality and English (as the lingua franca) because the return is high for these skills.

Distinguishing origin and destination countries and arguing in analogy to a neoclassical model of international trade, we will therefore find origin countries specializing in higher education in tourism (HTEE) while destination countries will specialize in vocational training and professional education in tourism (VTT). Assuming a comparative advantage of origins in higher education (due to a well developed university system) and a natural resource based comparative advantage of destinations in hospitality industry, and due to the interaction with the local labor market with VTT, an equilibrium might occur. Our first scenario can be illustrated by the following Figure 4 .

Figure 4: A simple model of Tourism Education and Location

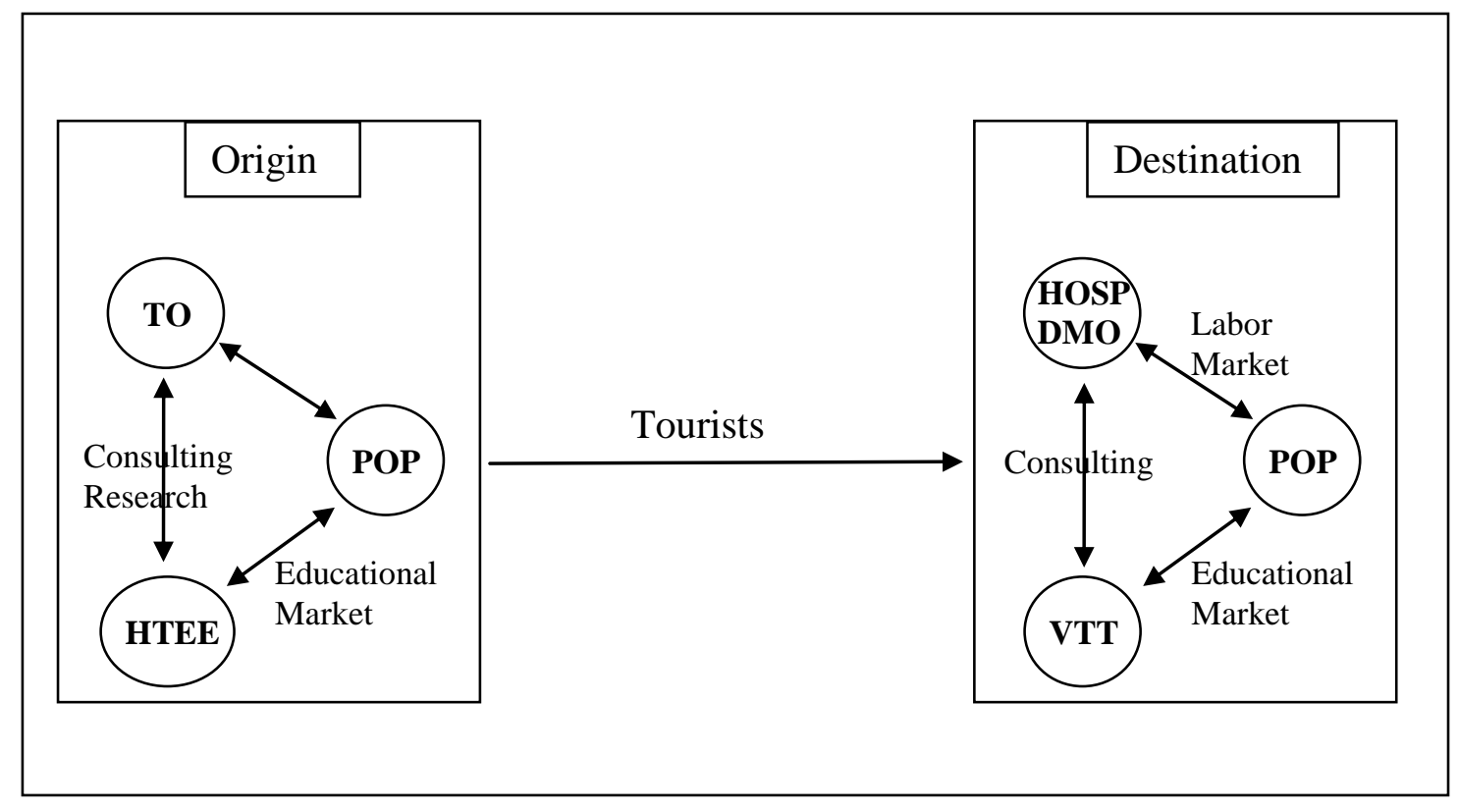

Tourism growth in destination countries might also trigger increasing activities targeted at the "live there" phase of the tourism experience, resulting in a growing leisure, entertainment, culture and event industry. This industry together with destination management organizations would then express a demand for respective research and higher education with the consequence of HTEE arising also at destinations. 
While there is some relevance in this theory given the distribution of HTEE programs as illustrated above, this equilibrium story has an obvious flaw, however. The traditional and in quantitative terms still the most important tourism destination countries are European countries and the US, hence developed economies which are at the same time the most important origin countries. And indeed also VTT and hospitality schools have first emerged in these countries. This can disturb the described equilibrium in a relevant way, as the simultaneous presence of HTEE, VTT, TO, DMO and hospitality (HOSP) creates a strong competitive advantage (probably even in form of a cluster). As a consequence, pure destination countries might find themselves in a situation where their labor force expresses a demand for education abroad. This second scenario is illustrated in Figure 5.

Figure 5: A revised model

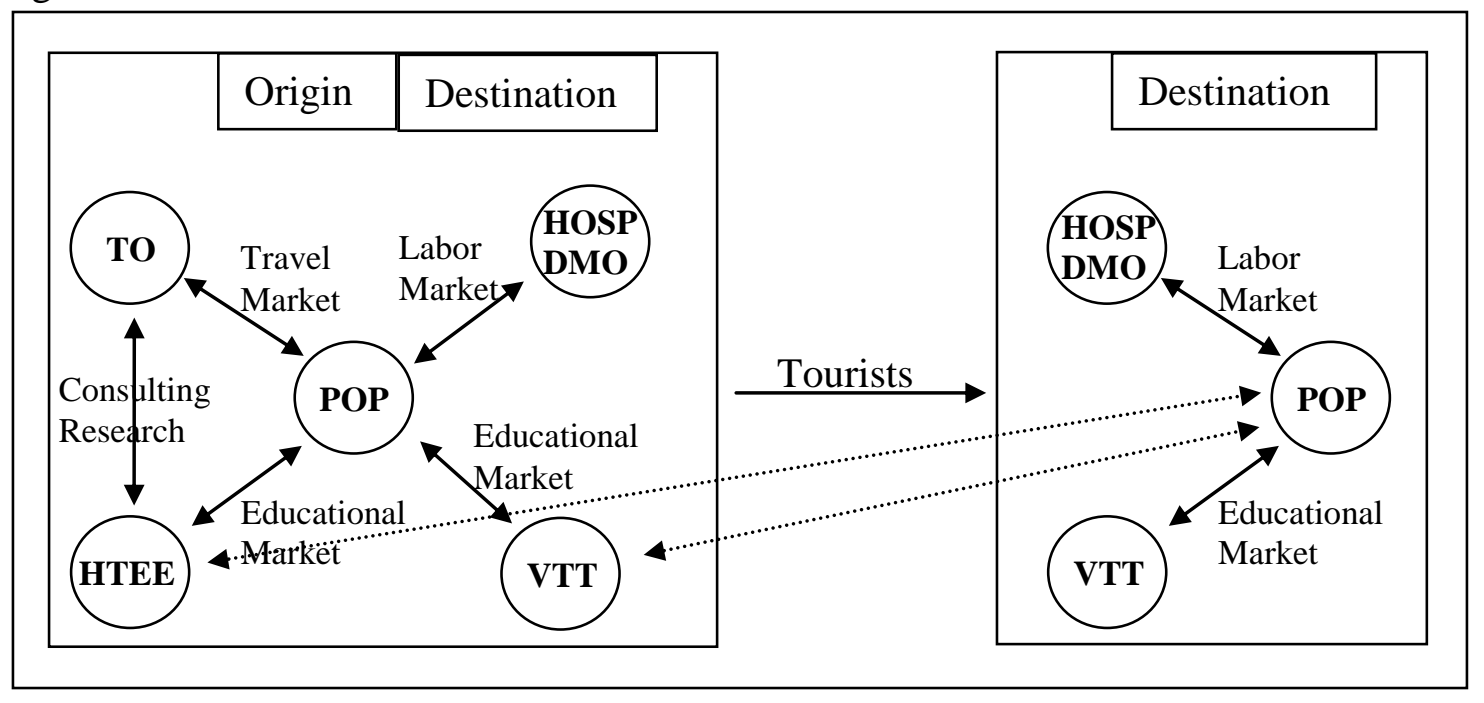

If moreover consulting and research is concentrated in the "strong" countries, the pure destinations risk to remain with the hospitality industry only. But the dynamics might not only work in disfavor of the destination countries via the local labor market, but also via general tendencies present in a globalized industry.

In rich countries the tourism sector with its low productivity and labor intensive production struggles to pay competitive salaries, and with its long and irregular working hours, does not offer attractive working conditions. As a consequence, investors seek for cheap labor and offer jobs with relatively low social prestige. The consequences are fundamental structural problems and competitive challenges. The tourism industry responds in two ways which both will reinforce the logic of concentration of HTEE in the rich countries. First, the industry under structural pressure will demand research, knowhow and managerial skills on company and destination levels, and the outgoing industry (tour operators, air transport companies, investors placing their capital in tourism development in poor countries) demand-similar competencies. Population invests in skills related to tourism market analysis and management because the return on this kind of 
human capital is high due to the demand from industry. Second, an important concentration of capital is present not only in the industry catering for the "get there" phase (large tour operators and transport companies). Large real estate developers promoting whole resorts and hotel and restaurant chains present in all relevant destinations around the globe are operating from the rich and competitive countries. The same holds for the "live there" phase. Event management, MICE competence, but also supply in the general leisure, culture and architecture industry, are increasingly operated by large companies and on a global scale. All this will enhance the concentration of HTEE and most probably also VTT in the countries already dominating the sector today.

The hypothesis advanced here is that scenario two will only materialize once the pure destinations undergo a significant economic development outside of tourism, start growing and hence become tourism origins themselves. E.g. HTEE will increasingly be offered in countries like e.g. Brazil, China, India and eventually regional markets for HTEE will form with competitive advantages regarding the cost of education, and geographical vicinity and cultural similarity. Countries without significant FDI will remain tourism destinations and hence eventually become markets for hospitality formation. The future will have to show whether fast growing economies will, with economic growth and a sharp rise in outgoing tourism, develop along a path similar to European countries and thus catch up with the leaders.

\section{Limitations and future research}

The limitation of this research is concerned with the data collection. The data collection instrument was limited to a set of graduate programs in tourism taught in English, identified on the World Wide Web and active in the fall of 2006. Future research should expand the data set to bachelor degrees, (as well as programs in national languages) since education at undergraduate level is more predominant.

\section{Conclusions}

The formation of middle and higher management personnel is increasingly important for economic activities exposed to worldwide competition - and the tourism industry is no exception. Investment in human capital determines to a significant extent the competitiveness and growth of national industries and hence their position in the concentration/dispersion process inherent in globalization. This paper therefore considers the spatial distribution of higher education in tourism and its correlation with the distribution of the industry itself. The specific focus is on higher tourism education in English because it is our belief, that global competition in higher education is tightly linked to the lingua franca.

The work is based on a sample of 112 masters programs worldwide and the main findings are that only 4 out of 112 programs are offered by countries which are not in the top 20 tourism countries with respect to their absolute importance in terms of departures and/or arrivals. We therefore conclude that higher tourism education in English is closely related to the importance of a country's tourism. But countries competing on these educational markets are not only important tourism countries, they are also wealthy - only five of them are not in the $25 \%$ richest nations group. Finally, Europe, accounting for more than 
half of international tourism departures as well as arrivals offers also more than half of the HTEE programs.

Given these results we develop two contrasting scenarios for the future distribution of program: a concentration scenario and a more spatially equilibrated one. The critical factors are mobility of students and faculty, the level of wealth and the importance of tourism. When students are more mobile than teachers, programs will be concentrated in few wealthy countries which are also important tourism countries. In the alternative scenario, programs and teachers will follow students and, consequentially, distribution of higher education as well as tourism development and wealth will be distributed in a more equitable way. This latter scenario will only materialize, however, if outgoing tourism itself is developing in many countries as a response to increasing wealth.

We conclude that the distribution of higher education in tourism among countries is depending on the one hand on the spatial strategies implemented by important suppliers (e.g. top programs from leading universities outsourcing to developing educational markets), and on the other hand on growth and welfare in emerging economies and the economic and educational policies implemented there. 


\section{Bibliography}

Barro, R.J. and Sala-i-Martin, X. (1999). Economic Growth, MIT Press, Cambridge, MA

Benhabib, J. and Spiegel, M.M. (1994) "The role of human capital in economic development. Evidence from aggregate cross-country data", Journal of Monetary Economics, Vol. 34 No. 2, pp.143-173

Blight, D.(1995) International Education: Australia's potential demand and supply: IDP Education Australia, Canberra.

Cubillo, J. M., Sanchez, J. and Cervino, J. (2006) International students' decision-making process, International Journal of Educational Management, Vol. 20, No. 2, pp. 101-115

Lam, T. and Xiao, H. (2000) Challenges and constraints of hospitality and tourism education in China, International Journal of Contemporary Hospital Management, Vol. 12, No. 5, pp. 291-295

Landes, D. (1998) The Wealth and Poverty of Nations. Why Some Are So Rich and Some So Poor, Little, Brown \& Co., London

Maggi, R. and Valeria Croce (2005) The "Lugano Tourism Indicator" - A Competitiveness Indicator for City Tourism Destinations in Europe, in "The Future of City Tourism in Europe", WTO, Paris

Ritchie, B. K. (2003) Managing Educational Tourism, Channel View Publications, Clevedon

Stevens, P. and Weale, M. (2003), Education and Economic Growth, Discussion Paper, National Institute of Economic and Social Research, London

Wolff, E. and Gittelman, M. (1993), "The Role of Education in Productivity Convergence: Does Higher Education Matter?”, in Szimai, A., van Ark, B. and Pilat, D. (Eds.), "Explaining Economic Growth", Elsevier Science Publishers, Amsterdam.

World Economic Forum (2007) The Travel \& Tourism Competitiveness Report 2007. Furthering the Process of Economic Development (Jennifer Blanke \& Thea Chiesa eds.), WEF, Geneva 


\section{Appendix}

Figure A1: Per capita expenditures and GDP (in logs) for 200 countries 2003

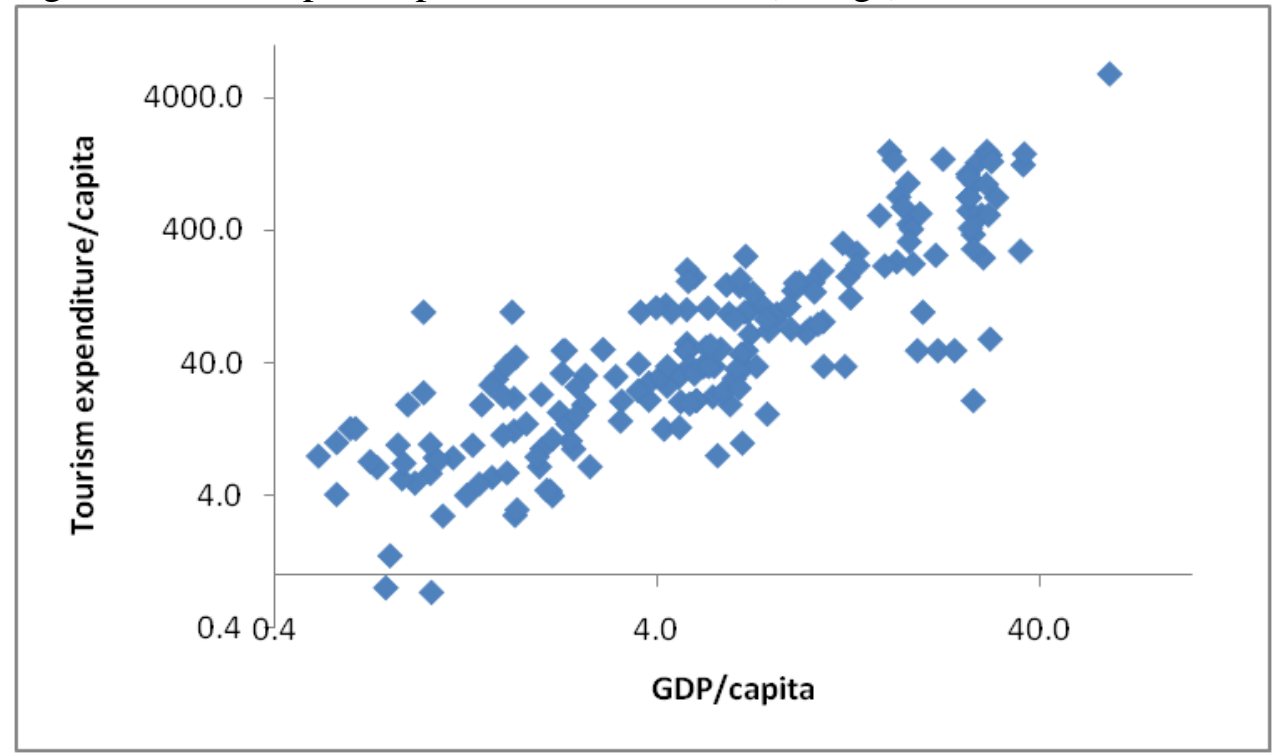

Figure A2: Per capita receipts and GDP (in logs) for 200 countries 2003



